\title{
Dot lasers: isotropic droplets in a cholesteric matrix, and vice versa
}

\author{
${ }^{1}$ Dudok T. H., ${ }^{1}$ Savaryn V. I., ${ }^{2}$ Fechan A.V., ${ }^{2}$ Cherpak V. V., \\ ${ }^{3}$ Pansu B. and ${ }^{1,3}$ Nastishin Yu. A. \\ ${ }^{1}$ Vlokh Institute of Physical Optics, 23 Dragomanov Street, 79005 \\ Lviv, Ukraine \\ ${ }^{2}$ Lviv Polytechnic National University, 12 S. Bandera Street, \\ 79013 Lviv, Ukraine \\ ${ }^{3}$ Laboratoire de Physique des Solides, UMR 8502, Universite Paris-Sud, 91405 \\ Orsay, France
}

Received: 03.11 .2014

\begin{abstract}
We have measured lasing spectra from dye-doped droplets of an isotropic liquid located in a cholesteric matrix ('inverted' suspension) and an 'inverse' system, dye-doped cholesteric droplets in an isotropic liquid ('conventional' suspension), with the both systems involving the same cholesteric and isotropic liquid components. For the conventional suspension, we have collected the lasing spectra for about 200 droplets and found that the lasing lines are clearly separated into three groups located at the short-wavelength and long-wavelength edges of a photonic band gap ( $\mathrm{PhBG}$ ) and inside the $\mathrm{PhBG}$. The latter ('forbidden') line is observed for all of the droplets under examination. Occasionally, it can coexist with one or both of the lines located at the short- or/and long-wavelength PhBG edges. We have shown for the first time that, for the inverted isotropic droplets in the cholesteric matrix, a single lasing line is located at the short-wavelength PhBG edge. This reveals a PhBG-nature of that line and corresponds to a zero scalar orientational order parameter for the dye molecules placed in the isotropic liquid.
\end{abstract}

Keywords: point light sources, mirrorless lasing, mirrorless lasers, photonic bandgap edge lasing, dye-doped cholesteric liquid crystals, liquid crystal lasers, dot lasers

PACS: 42.55.Mv, 42.55.Sa, 42.55.Tv, 42.70.Qs, 61.30.-v, 77.84.Nh, 78.60.Lc

UDC: $538.958+535.343 .32+681.7 .069 .2+52-626$

\section{Introduction}

Lasing droplets are attractive systems for fabricating micro-sized light sources. Micrometer sizes of those droplets and omnidirectional mirrorless character of their laser emission allow one to regard them as promising point laser sources. There might be at least two possibilities for mirrorless lasing of fluorescent liquid droplets. If a liquid drop is optically denser than a liquid matrix, in which it is freely suspended, the drop represents a natural mirrorless micro-resonator due to total internal light reflections. It provides light amplification of stimulated emission of radiation and reveals morphology-dependent resonant modes, which are also called as whisperinggallery modes [1, 2]. Morphology-dependent resonant lasing in dye-doped droplets is possible for both isotropic [3] and liquid-crystal [4] spherical droplets. There is another possibility based on photonic band-gap (PhBG) lasing in cholesteric liquid crystals (ChLCs) $[5,6]$. So, a drop considered in Ref. [6] represents only a proper container for a gain medium. Here the conditions for lasing are governed by selective multiple light reflections in an orientationally periodical cholesteric structure. They are met if the fluorescence emission band (FEB) of the dye molecules 
dissolved in the ChLC overlaps with the cholesteric selective reflection band (SRB), which is a PhBG for the emitted light. By definition, the notion of the PhBG implies that the light emission inside this gap is forbidden [7]. The density of states for the emitted photons becomes zero inside the spectral region of the PhBG but drastically increases on its edges and then oscillates with decreasing amplitude outside the PhBG on both its sides. High density of states of the emitted photons at the PhBG edges is a basis for laser generation in cholesterics [8].

In this article we propose yet another novel possibility for lasing in dye-doped isotropic droplets dispersed in a cholesteric matrix. Contrary to the case of dye-doped cholesteric droplets dispersed in an isotropic matrix [6] (further referred to as a conventional suspension), where the cholesteric serves as an internal Bragg reflector providing selective multiple reflections for the light emitted by the gain molecules inside the cholesteric droplet, here we deal with an inverted suspension. Namely, dye-doped isotropic droplets are embedded in a cholesteric matrix which serves as an external Bragg reflector for the light emitted from inside the droplet by the dye molecules. This factor makes a system akin to traditional lasers with external mirrors. We have detected the laser emission from both the conventional and inverted systems for the same pair of cholesteric and isotropic liquid materials, one of which being doped with a proper soluble dye (a hydrophobic dye for the cholesteric and a hydrophilic dye for the isotropic liquid).

\section{Experimental}

We use a commercially available short-pitch cholesteric mixture KET90700 (Jiangsu Hecheng Chemical Materials Co., Ltd., HCCH) as a basic cholesteric compound. Our measurements show that, at the room temperature, the SRB of this mixture is located between 480 and $540 \mathrm{~nm}$. Conventional and inverted suspensions are prepared using glycerol as an isotropic liquid immiscible with the LC material. To prepare the inverted suspension, we dope glycerol with Rhodamin 6G (Rh6G, purchased from Ltd. Sfera Sim, Ukraine) in the amount of $0.1 \mathrm{wt}$ \%. The FEB of the Rh6G dye dissolved in glycerol is located between 550 and $590 \mathrm{~nm}$, with a maximum falling on $570 \mathrm{~nm}$. To overlap the SRB of the cholesteric mixture with the FEB of the Rh6G dye, we add 15 wt. \% of a commercially available nematic E7 (purchased from Merck) to the basic cholesteric mixture KET90700. Further we label the mixture KET90700 + 15 wt. \% of E7 as an $I$ mixture thus highlighting that it is used for preparing the inverted suspension. The glycerol doped with the Rh6G dye has been stirred in the I-mixture to prepare the inverted suspension of the dyedoped glycerol droplets dispersed in the cholesteric matrix. A drop of the inverted suspension has been placed on a microscope glass slide between two stripe spacers (the thickness of $180 \mu \mathrm{m}$ ) and covered by a microscope cover glass.

To prepare the conventional suspension of the dye-doped cholesteric droplets in the glycerol matrix, we dope the cholesteric with a hydrophobic dye Nile Red (abbreviated hereafter as NR; available from Ltd. Sinbias, Ukraine). The NR dye manifests a maximum of its FEB in the cholesteric matrix at about $600 \mathrm{~nm}$ and the whole FEB extends approximately from 560 to $660 \mathrm{~nm}$. Since the SRB of KET90700 is located at the wavelengths shorter than those of the FEB for the NR dye, we add 21 wt. \% of the nematic E7 to the basic cholesteric mixture KET90700 in order to increase the cholesteric pitch and thereby overlap the cholesteric SRB with the FEB of the NR dye. The NR dye has been added to the mixture of KET90700 + 21 wt. \% of the E7 in the amount of $1 \mathrm{wt} . \%$. Further on, we label this composition as a $C$-mixture thus indicating that it is used for preparing the conventional suspension (the cholesteric droplets in the isotropic liquid immiscible with the cholesteric). The dye-doped cholesteric droplets are obtained by stirring the 
$C$-mixture in glycerol. A drop of the conventional suspension has been placed between a microscope slide and a cover glass separated by $180 \mu \mathrm{m}$ spacers. The cell with the suspension has been placed horizontally in a holder.

The laser generation has been achieved using a setup described in detail in Ref. [9]. For optical pumping we use a laser irradiation with the wavelength of $\lambda=532 \mathrm{~nm}$ obtained as a second-harmonic generation induced by a pulse solid-state laser in a crystalline material (the light wavelength $\lambda=1064 \mathrm{~nm}$, the pulse duration $\tau=6 \mathrm{~ns}$, the repetition period $T=1 \mathrm{~s}$, and the energy per pulse $15 \mathrm{~mJ})$.

\section{Results and discussion}

Upon pumping the dye-doped glycerol droplets embedded in the cholesteric matrix by the pulse green irradiation $(\lambda=532 \mathrm{~nm})$, we have detected the emission spectrum shown in Fig. 1. Narrow laser-like emission lines detected for different droplets correspond to the short-wavelength edge of the cholesteric PhBG for the I-mixture, which is determined following from the transmission spectrum of a planar cell (see Fig. 1b). At least two conclusions can be drawn from this fact. First, the data shown in Fig. 1 certifies that the observed emission line is a laser line of the PhBG-edge origin. Second, the location of the laser lines at the short-wavelength PhBG edge, rather than at its long-wavelength edge, indicates low orientational scalar order parameter $S$ of the dye molecules. This is indeed true as we have $S=0$ for the dye molecules dissolved in an isotropic liquid such as glycerol. It is worth reminding that, for the high enough positive values $0.5<S<1$, Ref. [10] predicts the lowest pumping threshold just for the laser line located at the long-wavelength $\mathrm{PhBG}$ edge. The laser line of the lowest threshold is expected to be at the short-wavelength edge of the PhBG for still lower $S$ values. These include the case $S=0$ that describes the absence of orientational order and $-0.5<S<0$ that corresponds to the case when the transition dipole moments of the dye molecules tend to align perpendicular to the long axes of the cholesteric molecules.

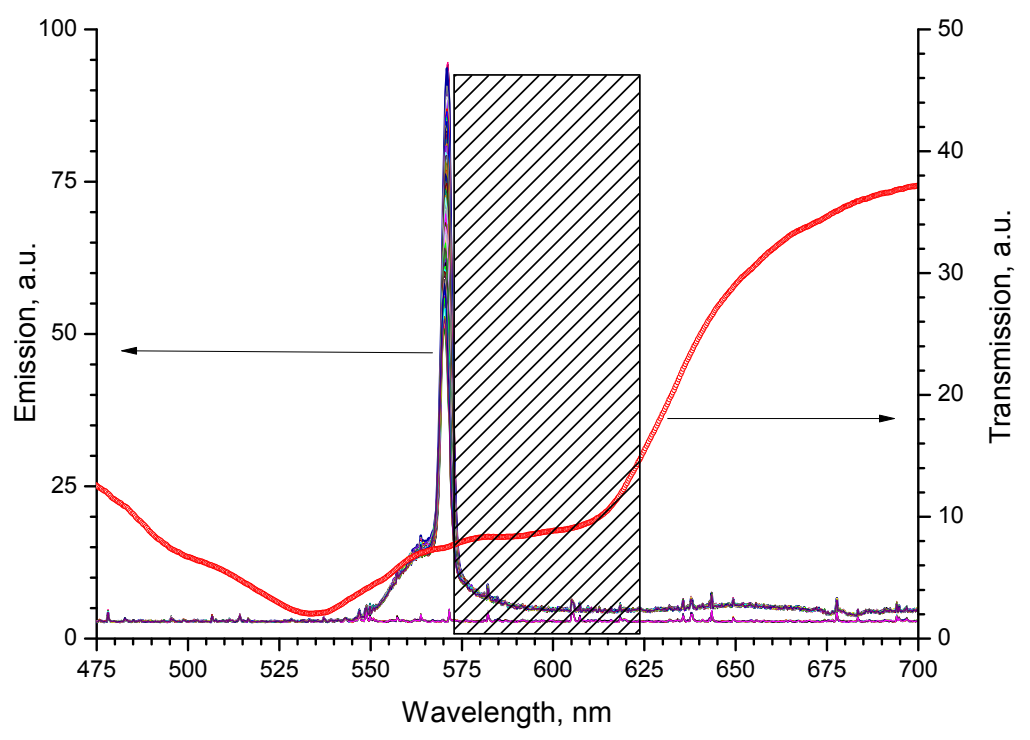

Fig. 1. Optically pumped emission spectrum of dye-doped (0.1 wt. \% of Rh6G) glycerol droplets dispersed in ChLC (inverted suspension) and optical transmission spectrum of the cell with planar surface alignment of ChLC molecules, as measured for the same cholesteric I-mixture. Dashed region indicates the cholesteric PhBG. 
The emission spectrum collected from optically pumped dye-doped cholesteric droplets dispersed in glycerol is shown in Fig. 2. To understand the location of the detected laser lines with respect to the cholesteric $\mathrm{PhBG}$, we show also the optical transmission (curve 2) and reflection (curve 3) spectra of the cell having a planar surface alignment of the ChLC molecules. The PhBG is indicated by a dashed spectral region in Fig. 2. For different droplets one detects different numbers of the laser lines, which vary from one to three. Two of these lines correspond to the PhBG edges, which are roughly located at 620 and $675 \mathrm{~nm}$, whereas the third line at $\lambda=631 \mathrm{~nm}$ falls inside the PhBG.

We have collected the spectra from about 200 droplets and found, quite surprisingly, that just this 'forbidden' line is detected for all of the droplets under test. For some droplets the line coexists with the lines located at the short- or/and long-wavelength edges. Usually its intensity is much higher than those typical for the two other lines, though this does not represent a strict rule. As a matter of fact, in some cases the lasing detected at the short- or long-wavelength PhBG edges remains much stronger. All the spectra shown in Fig. 2 demonstrate unambiguously that the laser lines detected by us correspond to the three groups, which are located respectively at the shortwavelength and long-wavelength PhBG edges, as well as inside the PhBG.

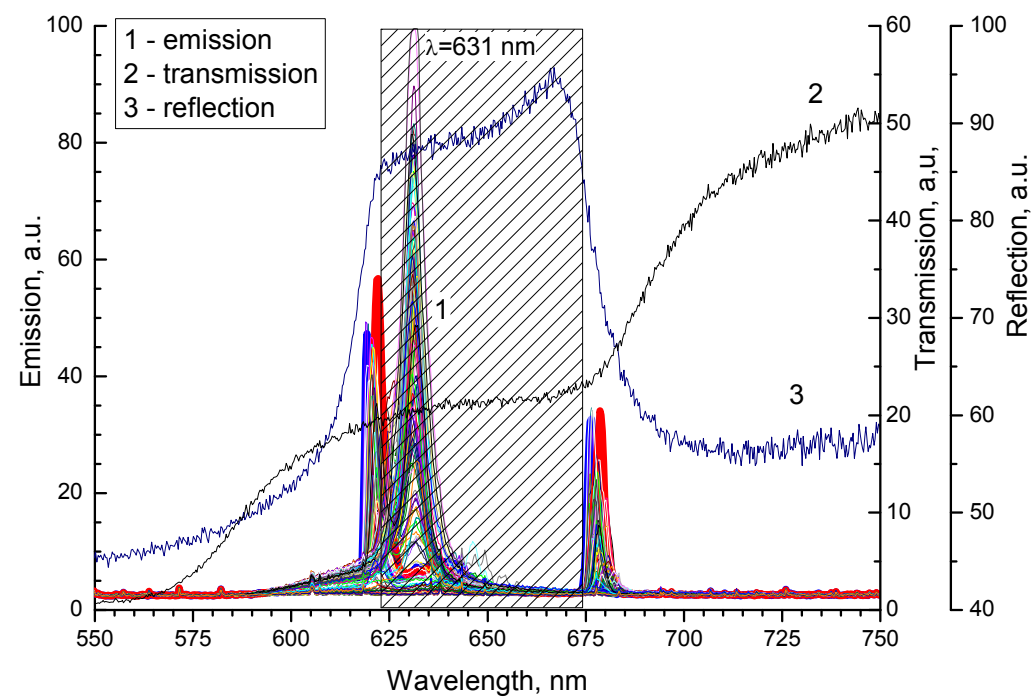

Fig. 2. Optically pumped emission spectrum (curve 1) of dye-doped ( 1 wt. $\%$ of NR) cholesteric droplets dispersed in glycerol (conventional suspension), and optical transmission (curve 2) and reflection (curve 3) spectra of the cell with planar surface alignment of ChLC molecules, as measured for the same cholesteric $C$ mixture. Dashed region indicates the cholesteric PhBG.

Polarization microscopic observations have proved that the cholesteric droplets suspended in glycerol (i.e., the conventional suspensions) show a so-called 'monopole' texture, with a disclination line running from the droplet surface to its centre. Such a texture unambiguously reveals tangential alignment of the cholesteric molecules at the droplet surface [11] and, consequently, the helical axis is roughly oriented along the droplet radii. This conclusion agrees with the numerous reports known from the literature, according to which glycerol induces planar alignment of thermotropic LCs at the interface (see, e.g., Ref. [12]). The uniform planar alignment of the cholesteric layers at the droplet interface favours selective multiple reflections of light emitted by the dye molecules under optical pumping. This statement is valid for both the conventional and inverted droplets. 
Regarding the optical geometry, the only difference between the two suspensions under test is that for the conventional droplets (i.e., the ChLC droplets in glycerol) the cholesteric layers are quasi-spherically packed inside the light-emitting droplet, whereas for the inverted droplets the cholesteric layers wrap the light-emitting droplet outside. In the both cases the dye molecules are inside the droplets. It is worth noticing that, in case of the conventional suspension, the cholesteric multiply reflects the light emitted by the dye molecules, which are located essentially deep in a bulk of the cholesteric medium. Hence, strictly speaking, this system has no analogues among the traditional lasers with artificial mirrors, which are always external with respect to a gain medium. In other words, the external mirrors in the latter case form a resonator cavity containing a gain medium, whereas in the former case (i.e., for the conventional suspension) the droplet surface and its shape are in fact of no importance for the laser generation as long as the cholesteric layers remain uniformly equidistant and properly aligned within a lasing volume which might be smaller than the total volume of the droplet.

Whether it is strictly true or not, this statement does agree with our observations of the anomalous laser line. We conventionally refer to this line as 'forbidden', since it falls inside the $\mathrm{PhBG}$, contrary to the two 'conventional' lines that properly 'girdle' the cholesteric PhBG edges. We therefore are led to suggest that the mechanism of the anomalous forbidden laser line located at $\lambda=631 \mathrm{~nm}$ might be linked to distortions of the cholesteric layers occurring in the droplets. One of the relevant explanations is that such distortions can be induced by contacting of the layers with the substrate. Moreover, one has to keep in mind that, even in an ideally spherical droplet, the cholesteric layers are curved and there is no evidence that the PhBG of the curved layers is the same as that for the flat cholesteric layers. Hence, a curvature of the cholesteric layers and defects available in their packing can be the origins of the forbidden line detected in this work in the lasing spectra of the conventional droplets. According to Ref. [13], high optical fields can also induce distortions in the ChLCs and so the same can be expected for the ChLC droplets. As reported in Ref. [6], the laser emission wavelength for the lasing ChLC droplets can be tuned thermally. Finally, one can hope to tune the lasing of the droplets with UV irradiation using photosensitive ChLCs, as it has been suggested, e.g., in Ref. [14] for a planar ChLC cell.

\section{Conclusions}

Both the 'conventional' (ChLC in glycerol) and 'inverted' (glycerol in ChLC) suspensions of the dye-doped droplets show an optically pumped laser emission. A single line located at the shortwavelength PhBG edge is detected for the inverted suspension. This reveals a PhBG-nature of the line and agrees well with a zero scalar orientational order parameter for the dye molecules placed inside the isotropic liquid. In case of the conventional suspension, the laser lines can be divided into the three groups, which are located at the short- wavelength and long-wavelength edges of the cholesteric PhBG, and inside this gap. The latter (forbidden) line has been documented for all the droplets under study. It can coexist with the lines located at the short- and long-wavelength edges of the PhBG.

\section{References}

1. Matsko A B, Savchenkov A A, Strekalov D, Ilchenko V S and Maleki L, 2005. Review of applications of whispering-gallery mode resonators in photonics and nonlinear optics. 4, IPN Progr. Rep. 15: 42-162.

2. Vahala K J, 2003. Optical microcavities. Nature. 424: 841-846.

3. Tzeng H-M, Wall K F, Long M B and Chang R K, 1984. Laser emission from individual 
droplets at wavelengths corresponding to morphology-dependent resonances. Opt. Lett. 9: 499-501.

4. Humar M and Muševič I, 2011. Surfactant sensing based on whispering-gallery-mode lasing in liquid-crystal microdroplets. Opt. Express. 19: 19836-19844.

5. Coles H and Morris S, 2010. Liquid-crystal lasers. Nature Photonics. 4: 676-685.

6. Humar M and Muševič I, 2010. 3D microlasers from self-assembled cholesteric liquid-crystal microdroplets. Opt. Express. 18: 26995-27003.

7. Yablonovitch E, 1987. Inhibited spontaneous emission in solid-state physics and electronics. Phys. Rev. Lett. 58: 2059-2062.

8. Kopp V I, Fan B, Vithana H K M and Genack A Z, 1998. Low-threshold lasing at the edge of a photonic stop band in cholesteric liquid crystals. Opt. Lett. 23: 1707-1709.

9. Dudok T H, Krupych O M, Savaryn V I, Cherpak V V, Fechan A V, Gudeika D, Grazulevicius J V, Pansu B and Nastishin Yu A, 2014. Lasing in a cholesteric liquid crystal doped with derivative of triphenylamine and 1,8-naphthalimide, and optical characterization of the materials. Ukr. J. Phys. Opt. 15: 162-172.

10. Schmidtke J and Stille W, 2003. Fluorescence of a dye-doped cholesteric liquid crystal film in the region of the stop band: theory and experiment. Eur. Phys. J. B. 31: 179-194.

11. Nastishin Yu A, Kléman M, Malthête J and Nguyen H T, 2001. Identification of a TGBA liquid crystal phase via its defects. Eur. Phys. J. E. 5: 353-357.

12. Kleman $\mathrm{M}$, Lavrentovich $\mathrm{O} \mathrm{D}$ and Nastishin $\mathrm{Yu}$ A. Dislocation and disclination in mesomorphic phases, Vol. 12, in 'Dislocations in Solids', Ed. by F R N Nabarro and J P Hirth, Elsevier, 147-271 (2004).

13. Morris S M, Ford A D, Pivnenko M N and Coles H J. The effects of reorientation on the emission properties of a photonic band edge liquid crystal laser. J Opt. A: Pure Appl. Opt. 7: $215-223$.

14. Ilchishin I, Lysetskiy L, Mykytiuk T, Serbina M and Chilaya G, 2011. UV-radiation controlled tunable cholesteric dye laser based on an azoxy nematic matrix. Mol. Cryst. Liq. Cryst. 542: 221-226.

Dudok T. H., Savaryn V. I., Fechan A.V., Cherpak V. V., Pansu B. and Nastishin Yu. A. 2014. Dot lasers: isotropic droplets in a cholesteric matrix, and vice versa. Ukr.J.Phys.Opt. 15: 227-232.

Анотація. Проведено вимірювання спектрів лазерної генераиії для забарвлених краплин ізотропної рідини в холестеричній матриці (“інвертованоі”" суспензіі) та для забарвлених холестеричних краплин в ізотропній рідині (“звичайної” суспензіі). Обидві системи відповідають єдиній парі матеріалів - холестерику та ізотропній рідині. Для звичайної суспензії одержано лазерні спектри для близько двохсот краплин і встановлено, щзо набір лазерних ліній чітко розділений на три групи, розташовані на коротко- $і$ довгохвильовому краях фотонної забороненої зони (ФЗ3) $і$ всередині неї. Лінія всередині ФЗЗ (т. зв. “заборонена” лінія), яка спостерігається для всіх досліджених крапель, в деяких випадках співіснує з однією або двома лініями на коротко- та довгохвильовому краях ФЗ3. Вперие показано, щзо для інвертованих ізотропних крапель у холестеричній матриці спостерігається одна лазерна лінія на короткохвильовому краї Ф3З. Це підтверджує ї̈ Ф33-природу та відповідає нульовому скалярному орієнтаційному параметру порядку для молекул барвника в ізотропній рідині. 